\title{
Aconselhamento Psicológico como Construção Social
}

\author{
Laura Vilela e Souza \\ Universidade de São Paulo, SP, Brasil.
}

\begin{abstract}
Resumo: Este trabalho tem como objetivo apresentar as contribuições da perspectiva construcionista social para se pensar o campo do Aconselhamento Psicológico. Os principais pressupostos construcionistas sociais na área da psicologia social e da terapia familiar são colocados em diálogo com as definições contemporâneas de Aconselhamento Psicológico a partir da crise pós-moderna vivida nessa disciplina. Considerando-se a inexistência de estudos nacionais no tema, as teorias construcionistas sociais utilizadas no campo do aconselhamento em outros países são brevemente apresentadas e as produções internacionais da área cujos autores assumem o uso de aconselhamento em uma perspectiva construcionista social são discutidas. Esses aspectos servem de base para o tecer de algumas considerações críticas sobre o uso dessa perspectiva no campo do Aconselhamento e para proposição do Aconselhamento Psicológico como uma prática de produção de sentidos sobre um plano de ação de reconexão de pessoas, redes e instituições, com a inclusão de múltiplos protagonistas e com o profissional como facilitador desse processo conectivo, como parceiro na redescrição do sofrimento individual em termos de agenda de transformação social.
\end{abstract}

Palavras-chave: Aconselhamento Psicológico, Construcionismo Social, Estudo Teórico.

\section{Counselling Psychology as Social Construction}

\begin{abstract}
This paper aims to present the contributions of the social constructionist perspective to the understanding of Counselling Psychology. The main social constructivist assumptions in the field of social psychology and family therapy are put into dialogue with the contemporary definitions of Counselling Psychology, in view of the postmodern crisis experienced by this discipline. Considering the lack of Brazil-wide studies on the subject, we briefly present some social constructionist theories used in the field of counselling in other countries. Additionally, we discuss international studies whose authors address the use of counselling from a social constructionist perspective. These aspects provide the basis for critical considerations on the use of this perspective in the field of Counselling. They also enable us to propose Counselling Psychology as a way to produce meaning in an action plan for reconnecting people, networks and institutions, with the inclusion of multiple protagonists and professionals acting as facilitators of this connective process and as partners in the redescription of individual suffering in a social transformation agenda.
\end{abstract}

Keywords: Psychological Counselling, Social Constructionism, Theoretical Study. 


\section{Asesoramiento Psicológico como Construcción Social}

Resumen: Este trabajo tiene como objetivo presentar las contribuciones de la perspectiva construccionista social para pensar el campo del Asesoramiento Psicológico. Los principales supuestos del construccionismo social en el área de la psicología social y de la terapia familiar se ponen en diálogo con las definiciones contemporáneas de Asesoramiento Psicológico a partir de la crisis posmoderna vivida en esa disciplina. Al considerar la inexistencia de estudios nacionales en el tema, las teorías construccionistas sociales utilizadas en el campo del asesoramiento en otros países son brevemente presentadas y las producciones internacionales del área cuyos autores asumen el uso de asesoramiento en una perspectiva construccionista social son discutidas. Estos aspectos sirven de base para el tejer de algunas consideraciones críticas sobre el uso de esa perspectiva en el campo del asesoramiento y para la proposición del asesoramiento psicológico como una práctica de producción de sentidos sobre un plan de acción de reconexión de personas, redes e instituciones, inclusión de múltiples protagonistas y con el profesional como facilitador de ese proceso conectivo, como aliado en la re descripción del sufrimiento individual en términos de agenda de transformación social.

Palabras clave: Asesoramiento Psicológico, Construcionismo Social, Estudio Teórico.

Como afirmam Strawbridge e Woolfe (2010) na abertura da terceira edição do Handbook of Counselling Psychology, localizar profissionalmente e definir intelectualmente Aconselhamento Psicológico é uma tarefa complexa. Desde seus primórdios, essa é uma disciplina psicológica rebelde às formatações e avessa a uma identidade coerente e estável, uma vez que sua história é marcada pela exploração de suas incoerências, pelo embate entre epistemologias díspares na sua definição, pela polêmica de suas semelhanças e diferenças com outras disciplinas psicológicas e pela problematização de seu próprio nome e objeto de estudo.

Nos primórdios dessa disciplina nos Estados Unidos da América nos anos da década de 1950, o uso da teoria traço-fator definia um Aconselhamento Psicológico (AP) preocupado com sua cientificidade, com um olhar psicométrico e psicodiagnóstico do ser humano, posicionando o conselheiro como alguém que, a partir de seu conhecimento especializado, orienta e conduz o cliente a encontrar melhores formas de se adaptar ao mundo (Altmaier, \& Ali, 2012). Como salienta Schmidt (2009), essa teoria define AP como um processo educativo e normativo que justifica o poder do profissional como especialista sobre a vida do outro, e justifica, inclusive, o próprio nome "aconselhamento".

Mas dar conselhos deve ser o papel do profissional de AP? Qual a implicação ética de se posicionar o cliente como passivo nesse processo? Será possível um processo de aconselhamento que seja uma ajuda para o cliente chegar, ele próprio, à reflexão de como deve viver a própria vida e responder a seus dilemas? Quais as consequências de se pensar uma relação de ajuda quando o profissional faz uso de seu conhecimento circunscrito de mundo para orientar o outro? Essas questões fomentaram os movimentos de contraposição à definição de AP derivado do uso da teoria traço-fator. Carl Rogers, ator fundamental nesse movimento crítico, desestabilizou a área com seu entendimento de que um atendimento em AP deveria ser uma relação de ajuda em um espaço acolhedor e permissivo, com o foco no cliente e não no problema ou na busca por diagnósticos, com atitudes profissionais de empatia, autenticidade, congruência interna e aceitação positiva do cliente e seus conteúdos, o que criaria uma atmosfera facilitadora para o desenvolvimento da pessoa e para o seu protagonismo nas decisões em sua vida.

Com a entrada de Rogers nesse cenário, "há um transbordamento daquilo que era, e é ainda, muitas vezes, considerado clínico" (Schmidt, 2009, p. 7). O que antes separava AP de psicoterapia - o primeiro focando em dilemas individuais circunstanciais, com o uso de testes para colaborar nesse processo em um atendimento breve; e o segundo focando o atendimento de situações graves, com a necessidade de "aprofundamento" e extensão do processo na intenção de mudanças de personalidade - agora os torna indistintos (Sch- 
midt, 2015). AP, nessa lógica, passa a ser a disciplina que pensa a relação de ajuda a qualquer pessoa em qualquer contexto. É a disciplina que tem como objeto de estudo a própria relação profissional-cliente, e que passará a pesquisar esse relacionamento, suas características, seus elementos formativos e sua influência no processo de mudança do cliente (Sheeffer, 1976). Godstein (2010) aborda esse e outros desacordos na área como característica do AP de resistência a autoridades classificatórias. Já Strawbrige e Woolfe (2010) somam-se ao coro daqueles que entendem que a diferenciação de AP das demais disciplinas psicológicas é tarefa árdua ou até infrutífera.

Schmidt (2009) escreve sobre "o jogo identitário" em AP contrapondo a busca moderna da "pureza dos modelos" com a valorização pós-moderna dos "híbridos" que essa disciplina produz. Dessa forma, a autora nos convida a acolhermos as "ambiguidades e ambivalências" em AP, o histórico de "desacomodações" disciplinares inaugurado com Rogers" e o "desconforto" com o seu nome, a partir da valorização dessa disciplina-indisciplinar, de uma "identidade que se processa entre lugares” (p. 16). Estar entre-lugares ou na "área de fronteira", como propõe a autora, é aproveitar da liberdade das não classificações, construindo AP a partir de uma posição "instável” (p. 17). Essa instabilidade, como reforça Schmidt, só é sinal de fraqueza frente a uma lógica disciplinar moderna em Psicologia que toma o mapa psicológico e suas divisões em áreas como reflexos "da realidade", e não como produções sócio-históricas contextualizadas e dependentes dos parâmetros, instrumentos e direcionamentos utilizados para as leituras dos terrenos psi. O alerta pós-moderno é para entendermos que qualquer definição do que venha a ser entendido como AP só pode ser compreendida e avaliada a partir do parâmetro escolhido para essa definição, a partir das comunidades de inteligibilidade que participam as pessoas que a definem e dos interesses sociais, éticos e políticos envolvidos nessa produção de sentidos.

A partir das influências pós-modernas, como mencionam Strawbridge e Woolfe (2010), AP assume-se, na atualidade, como uma disciplina que valoriza a multiplicidade teórica, resiste à metanarrativas, se mantém crítica à racionalidade científica e atenta às relações de poder e ideologias envolvidas na produção de conhecimento na área. Nesse cenário, a perspectiva construcionista social, justamente por afinar-se a tais posicionamentos pós-modernos, adentra esse campo de forma expressiva e inspira novas práticas (Clarkson, 1998; Coyle, 1998; Davy, 2010), sendo considerada uma abordagem "fortemente emergente" (Strawbridge, \& Woolfe, 2010) e grande aposta para desenvolvimentos futuros significativos na área (Haverkamp, 2012). Ainda que desde meados do início desse século e em vários países mais pesquisas sejam realizadas sobre aconselhamento e construcionismo social (Strong, 2000; Strong, 2005), no Brasil não se encontram estudos publicados que adotem essa perspectiva em AP.

Como resgata Schmidt (2009), a presença em diferentes países e especialmente nos Estados Unidos de centros de atendimento psicopedagógico aos estudantes nas Universidades permitiu com que a área de Aconselhamento Psicológico fosse explorada a partir de diferentes práticas e teorias. No Brasil, como afirma a autora, a ausência desses centros e a predominante orientação humanista dos coordenadores dos primeiros serviços de aconselhamento psicológico nas universidades brasileiras fez com que AP aparecesse nos primeiros currículos de cursos nacionais em Psicologia ligado à teoria rogeriana. Ao longo dos anos, as marcas desse histórico e a relevância das produções sobre AP nessas universidades, manteve a predominância de pesquisas e publicações sobre AP na abordagem centrada na pessoa, somando-se a publicações na perspectiva fenomenológica-existencial, mas sem expressivo investimento no estudo de AP a partir de outras teorias (Scorsolini-Comin, \& Santos, 2013).

Buscando fomentar uma discussão crítica sobre AP, este estudo tem como objetivo apresentar e discutir as contribuições que a perspectiva construcionista social pode trazer para se pensar esse campo, buscando compreender de que forma os pressupostos filosóficos do construcionismo inspiram e redefinem AP, de que forma essa perspectiva tem sido utilizada por teóricos e pesquisadores do campo, e quais os limites dessas construções e os desafios postos para o futuro dessa disciplina.

Para tanto, as definições dos principais pressupostos construcionistas sociais feitas por autores proeminentes na área da psicologia social e da terapia familiar (Gergen, 2009; Ibañez, 2001; McNamee, 2005) são colocadas em diálogo com as definições contemporâneas de AP a partir da crise pós-moderna vivida nessa disciplina. Em seguida, as teorias construcionistas sociais utilizadas no campo do AP são brevemente apresentadas. Além disso, as produções 
internacionais da área cujos autores assumem o uso de AP em uma perspectiva construcionista social são levantadas e discutidas. Por fim, esses aspectos são sintetizados e servem de base para o tecer de algumas considerações críticas sobre o uso dessa perspectiva no campo do AP.

\section{Aconselhamento psicológico e os pressupostos construcionistas sociais}

A entrada das apreciações construcionistas sociais nas ciências humanas já data de algumas décadas (considerando-se como um marco possível o artigo de Gergen de 1985, famoso pela apresentação de uma síntese do construcionismo social). Gergen (2009) apresenta as premissas de investigações construcionistas sociais: Primeira premissa: "Aquilo que consideramos como experiência do mundo não determina por si só os termos em que o mundo é compreendido" (p. 301). Segunda premissa: "Os termos com os quais entendemos o mundo são artefatos sociais historicamente situados de intercâmbios entre as pessoas" (p. 303). Terceira premissa: "O grau com que uma dada forma de entendimento prevalece ou se sustenta através do tempo não depende fundamentalmente da validade empírica da perspectiva em questão, mas das vicissitudes dos processos sociais" (p. 304). Quarta premissa: "As formas de compreensão negociadas são de uma importância crítica na vida social, na medida em que estão integralmente conectadas com muitas outras atividades das quais participam as pessoas" (p. 306).

As implicações dessas premissas para se pensar AP é a de que os termos que povoam essa disciplina reificam seus objetos. Subjetividade, racionalidade, habilidade, recurso interno, experiência, mundo mental, psiquismo são opções discursivas que constroem noções específicas sobre quem é o ser humano, como ele funciona e como podemos ajudá-lo. Tomar essas noções como representações de como as coisas são "na" realidade é perder de vista a historicidade de sua produção. Diferentes teorias em AP competem como visões distintas sobre o foco de sua atuação, seja ele o comportamento humano, a cognição, aspectos inconscientes, percepções, sentidos ou significados. Cada uma delas é legitimada em comunidades de inteligibilidade distintas cujas redes de atores produzem realidades, objetos, verdades, fatos, argumentos e evidências, levando, ao fim, a produção de diferentes APs que convivem em diferentes contextos linguísticos e interações. São essas redes que sustentam esses "existentes" em AP. Ibañez (2001), ao escrever sobre a proposta construcionista social em ciência, e ao argumentar que os objetos psicológicos não procedem da natureza humana, mas de nossas práticas de objetivação, alerta que essa afirmação não é o mesmo que questionar a existência das coisas, ou negar que exista uma realidade que impõe limites a nossos modos de conhecê-la. Mas que qualquer realidade só passa a existir para o ser humano a partir de seus modos de acessá-la. Não é possível, assim, separar realidade de conhecimento.

Strawbridge e Woolfe (2010) apresentam AP na contemporaneidade como uma disciplina que busca se construir a partir de parâmetros menos individualistas, menos profissionais centrados, com interesse no bem-estar das pessoas e não na busca por psicodiagnósticos e maior preocupação com o "estar em relação" do que com a "especialidade técnica". Podemos articular esses aspectos com as contribuições construcionistas sociais.

Com relação a parâmetros menos individualistas em AP, o foco na linguagem e não em elementos estruturais do "eu" do cliente responde a uma das principais críticas construcionistas em Psicologia, a saber, a crítica à noção de um "eu" autocontido; fruto de uma lógica que coloca o cliente como a célula indivisível última da sociedade, como fonte de ação e como separado de um mundo externo. Aposta-se, outrossim, no ser relacional (Gergen, 2009), em um "eu" que se produz momento a momento, que se constitui nas interações, que nasce das próprias formas utilizadas para narrar-se ou ser narrado, e, portanto, é dinâmico, múltiplo, flexível, aberto a renarrações e reconstruções. Novamente cabe a ressalva de que não se está falando em termos de uma natureza discursiva do "eu", mas que qualquer descrição de self só se garante em termos da legitimação de seu uso e não em sua fidedignidade com relação a como o "eu" é "realmente". O relativismo não é ontológico, mas epistemológico. Nosso apego à descrição essencialista de self nos impede de entender essa como uma das opções possíveis de entendimento do ser humano, em uma visão ocidentalizada e individualista. Pensar o eu a partir de metáforas relacionais é explorar as ações humanas em termos de corresponsabilização e não de culpabilização individual (McNamee, \& Gergen, 1999). Priorizar as explicações relacionais das ações humanas, com o cuidado de não cair em explicações deterministas sociais, não é tirar do cliente sua 
noção de agenciamento pessoal, mas criar metáforas que, em vez de falar em termos de intencionalidade individual, falem em ações conjuntas, em respostas sistêmicas, ligando os problemas individuais a condições relacionais e sociais mais amplas. A exploração de diferentes visões sobre a problemática do cliente é um contraponto às terapias tradicionais que buscam a singularidade das interpretações psicológicas.

Com relação ao questionamento do profissional como especialista sobre o cliente, Ibañez (2001) traz contribuições para se pensar AP a partir da crítica a uma Psicologia moderna que ao tratar seus conhecimentos de forma "ingênua" não reconheceu seu uso autoritário na definição de quem são as pessoas, seus males e caminhos para suas soluções. No campo do AP, podemos pensar que esse autoritarismo se configura na crítica ao uso do conhecimento especializado do profissional na condução do atendimento sem a participação do cliente. Mas mais do que isso, é entender que qualquer definição de ser humano permite algumas ações e restringe outras e que a justificativa para seu uso em AP não se sustenta mais na noção moderna de cientificidade. Questionar o status da produção científica não é desprezar seu valor, mas, como afirma Ibañez, é abrir a reflexão sobre as normativas que fazem parte dessas convenções e posicionar o psicólogo como responsável pelos efeitos que sua visão de mundo e prática produzem.

Com relação a ênfase no bem-estar do cliente e não na busca de doenças, Gergen e Warhuus (2001) apontam que ao deixar de se buscar a interpretação mais verdadeira sobre a problemática do cliente o profissional pode acolher a multiplicidade de possibilidades de construção "do real" e, assim, problematizar os efeitos negativos que as descrições de déficit pessoal podem trazer para a vida de uma pessoa. Ao se entender que os problemas não existem de forma independente de nossas interpretações é possível deixar de se focalizar os problemas para olhar para os recursos e potencialidades do cliente, para sua rede de apoio e de seu contexto. $\mathrm{O}$ foco nas potencialidades ao invés do déficit $\mathrm{e}$ histórias de insucesso é o entendimento de que "não são os problemas do mundo que determinam a nossa forma de falar [...] mas é através das nossas convenções linguísticas que nós determinamos que algo é um problema" (p. 50). A avaliação da intervenção a partir de seus efeitos pragmáticos dá o parâmetro da utilidade como alternativa ao da "verdade" dos fatos psicológicos, sendo que a definição do que vai ser útil deve ser uma coprodução profissional-cliente.

Com relação ao foco no "estar com" o cliente e não na especialidade técnica, é afirmar, como o faz McNamee (2005), que, "quando nos preocupamos com o que as pessoas estão fazendo juntas, o método e os modelos que utilizamos se tornam menos importantes do que trabalhar juntos para desenvolver futuros possíveis" (p. 11). Dessa forma, a ideia culturalmente aceita de profissionalismo como sinônimo de adoção de um modelo bem-sucedido de atendimento, como explica a autora, é substituída pela avaliação das teorias e métodos de intervenção como formas de envolvimento profissional-cliente, sustentadas por práticas específicas. A partir de uma postura de "incerteza produtiva" o profissional poderá "selecionar uma teoria ou técnica como uma opção de prática (como oposta a uma verdadeira opção) aumentando nossa habilidade para nos envolvermos relacionalmente com os clientes" (p. 26).

Assim, pensar AP como construção social ${ }^{1}$ implica um duplo movimento. O primeiro é o de reconhecer suas teorias como construções e não como representações da realidade, avaliando as implicações de seu uso, o lugar que o profissional ocupa no atendimento, as relações de poder que nele se desenvolvem e os potenciais de ação humana que promovem. É um movimento metateórico. O segundo movimento é o de, considerando-se que teorias são opções discursivas (McNamee, 2005), podemos explorar outras construções teóricas que possam performam AP a partir da resposta às críticas que se colocam no campo na atualidade. A criação teórica, nesse caso, responde a crítica de Ibañez (2001) de que ocupar um lugar de relativismo radical em ciência não é, de forma alguma, sinônimo de passividade ética ou política. A postura filosófica construcionista social entende ética como a constante posição de reflexividade sobre o caráter construído das teorias, responsabilizando teóricos e profissionais pelas construções de mundo que fabricam e pela forma que respondem aos dispositivos de dominação e desigualdades sociais, as diferenças culturais das pessoas e a sua diversidade.

Nomear uma teoria como construcionista social é um desafio na medida em que as propostas construcio-

\footnotetext{
${ }^{1}$ Um erro comum de entendimento do construcionismo social é o de entender que essa perspectiva faria uma afirmação de que "as coisas" são de natureza social. Essa é justamente a diferença entre se falar em termos de "AP como construção social”, como está colocado no título deste trabalho, e não "a construção social do AP".
} 
nistas se propõem dentro de um movimento dinâmico e múltiplo em ciência (Souza, 2014), com autores que se aproximam em alguns pontos e se distanciam em outros (Burr, 2003), com autores que ainda que sejam reconhecidos como construcionistas e tenham suas teorias assim classificadas não se posicionam ou se posicionaram em vida como construcionistas (Rasera, \& Japur, 2004), pela crítica desse movimento à própria noção de teoria, que implica a ideia de representação de realidade e a preferência de muitos na área em se falar de construcionismo não como teoria ou abordagem, mas como perspectiva ou discurso (Guanaes-Lorenzi, Moscheta, Corradi-Webster, \&. Souza, 2014) ou como postura filosófica (McNamee, 2005). Reconhecendo esse desafio e suas razões é possível identificar a menção e uso de algumas teorias terapêuticas como respondendo a uma sensibilidade construcionista social, sendo elas: Terapia Narrativa, Terapia Focada na Solução e Terapia Colaborativa. São também essas as teorias que têm inspirado as práticas no campo do AP em diferentes países.

\section{O uso das teorias construcionistas sociais no campo do Aconselhamento Psicológico}

Strong (2007) afirma que o início do uso das teorias construcionistas sociais em AP remonta ao início dos anos 2000, com o aumento crescente de sua presença nos currículos de graduação em Psicologia a partir dessa data. $\mathrm{O}$ autor menciona as duas principais influências do uso das teorias construcionistas no campo do AP: a de que o diálogo profissional-cliente constrói, sustenta e desconstrói os entendimentos do cliente sobre si mesmo e sua vida e a de que essa construção/desconstrução deve acontecer de forma colaborativa. Daí o foco do AP nas realidades conversacionais criadas na interação profissional-cliente.

Neimeyer (1998) aponta a Terapia Narrativa como a mais "consciente na adoção de um parâmetro discursivo na intervenção" (p. 11) dentre as teorias pós-modernas utilizadas em AP. Ele menciona os principais teóricos narrativos, Michael White e David Epston, e sua contribuição para o olhar do profissional sobre a forma como os clientes internalizam discursos culturalmente dominantes passando a olhar para si mesmos como culpados por problemas que poderiam ser lidos de maneira social, levando a diagnósticos de doenças mentais que separam as pessoas de suas redes de apoio e as alienam dos processos pelos quais podem obter a melhora.
White e Epston (1990) entendem as construções narrativas como as formas pelas quais as pessoas organizam suas experiências e dão sentido a elas por meio do relato. As narrativas têm para os autores caráter constitutivo, "modelam vidas e relações" (p. 29, tradução nossa). Ao estruturar essas narrativas, as pessoas fazem uma seleção de eventos que, segundo os autores, podem acabar se tornado narrativas dominantes sobre quem são e sobre suas vidas, deixando de lado uma riqueza não explorada de narrativas alternativas. A edição dessas narrativas e o aparecimento de relatos dominantes relacionam-se à noção de Foucault de verdades normalizadoras tal como nos lembra Rasera e Japur (2004):

há aspectos de nossas vidas que deixam de ser narrados, pois não se encaixam nos parâmetros descritos em tais verdades. A consideração do poder constitutivo destas narrativas dominantes traduz a sensibilidade construcionista desta proposta terapêutica aos valores promovidos por tais verdades (p. 433).

A partir da noção de narrativa dominante, Neimeyer (1998) propõe os objetivos do profissional de AP de ajudar o cliente a resistir a essas narrativas, externalizar o problema separando-o da identidade do cliente, examinar os efeitos dessas narrativas na vida da pessoa, dar extrema atenção aos momentos nos quais o cliente não está sob os efeitos negativos dessas narrativas (momentos de resistência), historiciar as conquistas do cliente com relação a elas, e recrutar pessoas (audiência) que possam colaborar, durante o processo de atendimento, na descrição de narrativas alternativas às dominantes trazidas pelo cliente. A partir da noção de narrativa dominante e de seu poder na limitação das possibilidades na vida das pessoas, o AP narrativo propõe ajudar o cliente a se libertar dessas narrativas e conquistar a autoria de sua vida.

Segundo Davy (2010), externalizar o problema do cliente é a negociação com o cliente de uma nova definição do problema que mostre que pessoa e problema são entidades separadas. Isso permite, segundo o autor, desconstruir o status de verdade das descrições de eu do cliente, permitindo que outras vozes e valores entrem na conversa em AP que possam contradizer o problema e ampliar formas de ação. Portanto, o profissional conduz um processo intencional de reavaliação e reorganização de narrativas. O AP narrativo 
critica a noção de self como autônomo, circunscrito, com necessidades internas, passando a tratar self como "em relação", "múltiplo" e "contingente". O processo de contar histórias participa da construção da própria noção de subjetividade.

AP como locus de reposicionamento do cliente frente aos discursos sociais acontece, de acordo com Winslade (2005) a partir dos seguintes passos:

1. Construção de confiança no relacionamento e exploração dos problemas que trazem a pessoa para o aconselhamento. 2. Desenvolvimento de uma conversa de externalização que desconstrua a história de problema e o localize no universo do discurso. 3. Mapeamento das posições discursivas que a pessoa é convidada na história do problema. 4. Identificação dos esforços da pessoa de resistência a ser posicionada dessa forma. 5. Investigação das preferências da pessoa pelas formas de reposicionamento que fariam a diferença. 6. Desenvolvimento de uma descrição dessa mudança de posição que esteja localizada na história pessoal, na comunidade de pertença e em discursos/conhecimentos alternativos que possam servir para sustentar a mudança de posicionamento face as afirmações persistentes dos discursos dominantes (p. 358, tradução nossa).

Como menciona Winslade (2005), as mudanças vividas pelo cliente não se dão a partir de uma origem cognitiva, mas são "públicas e sociais", implicando a forma como as pessoas respondem as nossas histórias. A noção foucaultiana de discurso assumida pela abordagem narrativa envolve, como menciona o autor, "uma série padronizada de sentidos e práticas sociais estabelecidas por meio de uma multitude de conversações (faladas e escritas) através de um cenário social amplo" (p. 357). Portanto, a possibilidade de externalizar o problema é a forma do indivíduo responder a esse cenário social mais amplo, renegociando posições de poder e produção de sentidos nos microcosmos relacionais. Das construções microssociais nascem mudanças macrossociais e discursos alternativos são criados para fazer frente aos discursos dominantes. Assim, a noção de mudança defendida na abordagem narrativa é a de que não é possível mudar de forma direta os discursos dominantes nos encontros de AP, mas a forma como o cliente se posiciona frente a eles. Essa forma de entendimento do processo de mudança é, para Winslade, o argumento do caráter político do aconselhamento.

A participação de audiências no processo de AP (convidar pessoas significativas para o cliente para participar da conversa), segundo Strong (2000), é uma rica colaboração da abordagem narrativa que permite conversas de caráter improvisado e espontâneo que ampliam as possibilidades de entendimento sobre $o$ que acontece com o cliente, além de permitir o envolvimento de outras pessoas na construção de ações de mudança, em uma aposta na dissolução de problemas no âmbito comunitário e não apenas individual.

Strong $(2005,2007)$ menciona a "postura de curiosidade" e a "postura de não saber" como contribuições relevantes da Teoria Colaborativa no campo do AP. Segundo Rasera e Japur (2004), a abordagem colaborativa é "uma das tentativas mais explícitas de construção de um modo de fazer psicoterapia pautado pelo referencial construcionista" (p. 435). Segundo Anderson (2016), a Teoria Colaborativa trata-se de "um modo de ser" na relação profissional-cliente que envolve uma investigação conjunta do que o cliente aponta como problemático, com o estímulo do profissional para que o cliente tenha curiosidade sobre novos modos possíveis de olhar para o problema. Nessa postura, a autora afirma o cliente como especialista de sua própria vida. A curiosidade é a postura que se coaduna com a noção epistemológica construcionista social de que não há uma melhor definição sobre a dificuldade do cliente que possa ser avaliada por parâmetros externos aos criados nas comunidades linguísticas das quais participam os envolvidos na conversa, no caso, profissional e cliente.

Para Anderson (2016), a postura de não saber refere-se à atitude humilde do profissional de não assumir que possui informações privilegiadas na interpretação do que vive o cliente. Curiosidade e saber coproduzido trabalham na contramão das noções tradicionais em Psicologia que, dada sua marca hereditária, colocam o profissional como investigador e conhecedor especializado sobre o outro. Neutralidade profissional não é elemento de legitimação da prática, ao contrário, há a posição profissional de "multiparcialidade, a qual considera e trabalha com todas as visões presentes no sistema simultaneamente [...] uma combinação das especialidades do terapeuta e do cliente" (Rasera, \& Japur, 2004, p. 436).

Segundo Martins, Santos e Rasera (2013), a Terapia Focada na Solução aproxima-se da proposta cons- 
trucionista nos seguintes aspectos: de que não há uma definição melhor ou mais fidedigna do problema do cliente na recusa do diagnóstico como único guia do profissional no atendimento, na preferência pelo olhar prospectivo com relação a vida do cliente, e na valorização das próprias definições do cliente sobre sua situação. Essa teoria, segundo seu principal autor, de Shazer (1985), propõe atendimentos breves, orientados para o futuro, com objetivos específicos, focado em soluções ao invés da exploração de problemas. $\mathrm{Na}$ busca por essas soluções, algumas técnicas são propostas, tais como a busca por soluções prévias já encontradas pelo cliente com relação ao tema abordado, busca de momentos de "exceção" nos quais tenha havido sucesso do cliente para lidar com a problemática em questão, perguntas voltadas para o futuro idealizado pelo cliente e não para o seu passado, e a pergunta do milagre, muito utilizada em AP (Strong, 2005; 2007).

A pergunta do milagre ajuda o cliente a descrever passos que ele possa começar a tomar na direção da solução idealizada. O propósito dessa pergunta é o de tirar a atenção do cliente de um presente de desesperança e desalento para um futuro no qual os problemas tenham sido superados. Essa pergunta pode ser rascunhada como: Imagine que você acordou e esse problema do qual estamos falando desapareceu. Qual seria o primeiro pequeno detalhe que você iria reparar para saber que ele desapareceu? Como as pessoas que gostam de você saberiam que esse problema desapareceu? Teve algum dia recente no qual você viveu algo parecido com como seria seu dia nesse dia do milagre? A partir dessas perguntas, são explorados quais pequenos elementos de mudança estão envolvidos na construção desse milagre e quais são as possibilidades de a pessoa já os incluir na sua vida.

Ao assumir essas teorias, corre-se o risco de reduzir a proposta de AP a elas, perdendo justamente o caráter do inesperado que surge da proposta construcionista de foco na linguagem. Nesse sentido, Strong e Nielsen (2008) entendem o uso dessas propostas a partir da avaliação de sua promoção no engajamento do cliente em conversas construtivas, na produção de novos sentidos e aberturas. É, segundo esses autores, a aposta em seu uso como alternativa ao entendimento de AP como encontro para coleta de informações, diagnóstico ou orientação. Esses autores, em pesquisa realizada a partir da análise de vídeo-sessões de atendimentos em AP a partir da perspectiva construcionista social, e de entrevistas com clientes e profissionais, concluíram que o uso dessas teorias levou à valorização da linguagem do cliente, à identificação de perspectivas de vida alternativas na conversa, à identificação de forças e recursos, ao desenvolvimento de um entendimento compartilhado e ao esforço para falar de forma diferente sobre a situação problemática:

Intervenções construcionistas em aconselhamento precisam ser iniciadas e coelaboradas de formas que ampliem as formas de compreensão do cliente, ao invés de ser a oferta dos conselheiros de uma perspectiva diferente que requeira que o cliente fale de fora de onde ele está produzindo sentido (Strong, \& Nielsen, 2008, p. 25, tradução nossa).

Em uma síntese integrativa, Saéz (2006) resume o que essas três teorias construcionistas (narrativa, colaborativa e focada na solução) têm em comum: a ideia de que a experiência da realidade se constrói com outras pessoas; a valorização do conhecimento produzido na conversa; a valorização do conhecimento do cliente; a construção de uma relação de respeito e colaboração; o posicionamento do cliente como protagonista do processo; o profissional com uma atitude transparente sobre suas próprias concepções, valores e teorias de mundo; e o interesse por todos aspectos da vida do cliente que mostram potencial de mudanças positivas, recursos, experiências exitosas passadas, e o que considera como valioso.

\section{Implicações do Aconselhamento Psicológico como construção social}

Algumas críticas com relação ao uso dessas teorias no campo da psicoterapia podem também ser pensadas para a crítica de seu uso no campo do AP. Rasera e Japur (2004) mencionam: o risco de se institucionalizar uma prática construcionista; o risco de reduzir o discurso construcionista a essas teorias; o risco da conversa ficar circunscrita ao âmbito local, sem sua articulação com o contexto macrossocial e problematização de noções de desigualdade e discriminação social; o risco do foco individualista ao se enfatizar "o senso de autocompetência do cliente" (p. 436); e o risco de reduzir discurso às falas individuais das pessoas.

Gergen e Warhuss (2001) destacam que olhar para a dimensão relacional nos atendimentos pro- 
fissionais abre uma série de possibilidades significativas frente aos malefícios que a individualização do problema e psicologização da vida do cliente trazem. Porém, a tradição de exploração das emoções, desejos, memórias, sonhos é uma tradição importante na história do ocidente, permeando a construção da noção de um mundo interno privado que pode ser um valor para o cliente. O cuidado que os autores mencionam tem relação com a avaliação de quando "encorajar realidades múltiplas é violar convenções culturais” (p. 49) e quando pode ser um recurso útil. Com relação ao foco apreciativo, o cuidado é para não desprezar as narrativas de problema trazidas pelo cliente, impondo um movimento de busca de recursos e soluções que pode não fazer sentido para a pessoa: "Os problemas são sempre devido a uma tradição de valores particular; retirar legitimidade a um relato do 'meu problema' é também pôr em dúvida a tradição que lhe está associada" (p. 51).

Com relação à abordagem narrativa, os autores supracitados entendem que o limite pode estar na troca de uma narrativa problemática por outra que acabe se reificando na vida do cliente, tornando-se "a" narrativa única e verdadeira, perdendo-se a riqueza da pluralidade de construções de eu. Além disso, não se deve tratar uma mudança no discurso como sinônimo de melhora, o que os autores justificam como sendo uma concepção individualista da mudança narrativa, não levando em conta o processo relacional de que deriva os sentidos do cliente e as dimensões corporais e materiais do domínio discursivo.

Com relação ao uso de técnicas derivadas da Terapia Focada na Solução, Martins et al. (2013) ressaltam o cuidado com a postura do profissional de restringir as conversas apenas ao âmbito da busca de soluções ou de conduzir o processo de forma hierárquica e não colaborativa. As intervenções dessa abordagem, de caráter mais diretivo, devem ser pensadas a partir da sua utilidade na conversa e não como foco necessário de desenvolvimento do processo de ajuda. Os autores apontam ainda que outros pontos de tensão que merecem destaque entre a terapia de foco na solução e a perspectiva construcionista social são de que no primeiro caso o foco está em mudanças de comportamento e não de discurso, tendo afastamentos epistemológicos entre as duas propostas; a terapia focada na solução entende relações como interações entre indivíduos isolados, e não como sendo também elas construções das práticas discursivas; a terapia focada na solução pensa mudança a partir de termos mentais e não está voltada para o entendimento de como os sentidos trazidos pelo cliente na conversa se relacionam com o contexto social mais amplo.

Quando o cerne do AP está localizado no formato de relacionamento profissional-cliente colaborativo, focado nos recursos do cliente, de caráter preventivo, voltado para o entendimento do cliente sobre o próprio sofrimento, e sensível às questões sociais que envolvem esse sofrimento, o construcionismo social é mais uma perspectiva que adentra a área para colaborar nessa demarcação (como outras teorias já o fizeram). A originalidade de sua contribuição pode ser referenciada em seu foco no contexto conversacional como produtor de realidades, na abertura para versões não essencialistas da identidade do cliente, e na postura de reflexividade sobre a produção de sentidos na conversa (Neimeyer, 1998).

Quando AP se diferencia das demais disciplinas psicológicas, como menciona Haverkamp (2012), não mais em termos de setting (AP realizado em poucos encontros) e características do cliente (clientes com dificuldades adaptativas e pontuais de vida), mas na forma como AP olha para o relacionamento profissional-cliente, concordamos com a autora que a maior contribuição do paradigma construcionista social para essa disciplina é o de permitir compreender esse relacionamento de forma menos estática do que a literatura da área costuma apontar: "é a mudança do foco da identificação de componentes do relacionamento em AP para os sistemas determinados por sentidos na relação" (p. 61). Por décadas, pesquisadores da área estudaram os elementos do relacionamento profissional-cliente em AP buscando compreender quais características do profissional levariam a relação de ajuda a acontecer, qual a melhor forma de falar, a melhor pergunta a ser realizada, o melhor modo de receber o cliente, a melhor sequência da conversa etc., em uma lógica de investigação de variáveis justificada por um paradigma moderno em ciência (Scheeffer, 1976). A lógica de investigação construcionista social não separa o que é do profissional e o que é do cliente, e busca entender de que forma os sentidos produzidos na conversa constroem noções de eu, de mudança, de mundo e, inclusive, noções sobre a própria relação profissional-cliente.

Considerando-se os impactos da entrada dos pressupostos construcionistas no campo do AP, Rudes e Guterman (2007) mencionam a dificuldade de mui- 
tos profissionais de abandonarem a noção de um "self verdadeiro", uma vez que essa noção é um valor na sociedade ocidental, locus da criação da própria disciplina. Os autores mencionam também a resistência de se abrir mão do olhar para o indivíduo como sujeito autônomo e independente para o olhar para os processos relacionais e seus efeitos na construção de eu. Como mencionamos anteriormente, a preferência por uma noção de "ser relacional" se sustenta na avaliação do sentido de seu uso nas relações. Gergen (2009) a defende por entender os prejuízos sociais do individualismo e pela necessidade de busca de alternativas.

Como já alertava Lyddon (1998), as produções construcionistas não devem estar isentas de avaliação em termos dos valores sociais que defendem. Essa autora problematiza a noção de empoderamento nas teorias construcionistas, afirmando não ficar clara a distinção entre as dimensões pessoais e políticas do empoderamento e o papel de cliente e profissional nisso. A autora chama a atenção para que o processo de AP seja mais do que apenas o ganho no desenvolvimento de habilidades e recursos pessoais, mas seja também espaço para os clientes se assumirem ativos nas mudanças sociais, sendo essa uma dimensão política do AP. Radicalizando o argumento, Clarkson (1998) faz frente aos questionamentos pós-modernos em AP encarando-os como oportunidade para se questionar em que medida continua fazendo sentido justificar um atendimento de AP em mundo de tanta injustiça social, propondo que essa disciplina se analise em termos da relevância de suas práticas frente às demandas das pessoas que atualmente buscam ajuda psicológica. Goldstein (2010), na esteira desse argumento, defende que o futuro da prática de AP deverá ser orientado para a atuação na comunidade, não perdendo de vista o embebimento social das pessoas, seus valores culturais e espirituais, esse último sendo um aspecto pouco valorizado em AP. Hansen (2012) e Morato, Barreto e Nunes (2009) apresentam a prática de AP em diversos contextos, para além do setting clínico tradicional, com o foco nas competências multiculturais do profissional e a defesa da justiça social.

Essas considerações sobre o futuro do AP também são ventiladas entre teóricos construcionistas sociais do campo da terapia que apontam a necessidade de práticas críticas e transformadoras:

alguns profissionais têm buscado desenvolver uma prática mais emancipatória e menos estig- matizadora, que não se sustente nas dicotomias, na noção de sujeito como entidade autônoma, independente e separada de todas essas transformações que a sociedade globalizada, pós-industrial e tecnológica vem apresentando. Tais práticas psicológicas se voltam para a coletividade e para o caráter relacional e performático na construção dos sentidos do mundo, dos valores e da sociedade (Camargo-Borges, 2010, p. 49).

McNamee (2015) propõe que se pense em práticas que explorem contextos relacionais e institucionais mais amplos, resgatando os vínculos relacionais e comunitários das pessoas que procuram ajuda e buscando, nessa mesma comunidade, outras versões para o sofrimento individual, versões mais sistêmicas e socialmente implicadas. Pensar AP a partir da proposta dessa autora do conceito de "presença radical", ou seja, de uma mudança de foco do profissional do cliente para o processo de relacionar-se, é ter a oportunidade de transformação dos discursos psicológicos de déficit individual para as opções de mudança social. AP não para tratar pessoas, mas para mudar instituições, com a atenção para os padrões sociais normativos que atravessam o processo de comunicação profissional-cliente.

Uma apropriação de AP a partir do resgate de seu histórico e do reconhecimento de suas definições contemporâneas permite pensar a prática de aconselhamento como uma relação de ajuda que se inicia em um microcosmo interacional, mas que deve se expandir a partir da identificação de seus atravessamentos macrossociais, das materialidades e sociabilidades que o perpassa. Uma aposta para novos estudos na área está na exploração do AP como espaço de redescrição do sofrimento individual em termos de agenda de transformação social, como espaço para se pensar estratégias de reconexão de pessoas favorecendo movimentos de resposta ao individualismo que impera em nossa sociedade contemporânea. Para responder a esse desafio, AP tem ao seu dispor a riqueza da produção de conhecimento de décadas sobre um modo de fazer psicológico não psicologizante. Já a perspectiva construcionista social oferece, por sua vez, um significativo conhecimento sobre a promoção de práticas dialógicas e colaborativas com estratégias para adesão a ações grupais, coletivas e de corresponsabilização. 


\section{Referências}

Altmaier, E., \& Ali, S. R. (2012). A view across the life span of counseling. In E. Altmaier, \& J. Hansen (Eds.), The Oxford handbook of counseling psychology (pp. 3-10). New York, NY: Oxford University Press.

Anderson, H. (2016). A postura filosófica: O coração e a alma da prática colaborativa. In M. Grandesso (Ed.), Práticas colaborativas e dialógicas em distintos contextos e populações: Um diálogo entre teoria e práticas (pp. 19-32). Curitiba: CRV.

Burr, V. (2003). Social constructionism. NewYork, NY: Routledge.

Camargo-Borges, C. (2010). Terapia social: Desenvolvimento humano e mudança social. Arquivos Brasileiros de Psicologia, 62(3): 1-114.

Clarkson, P. (1998). Counselling psychology: the next decade. In P. Clarkson (Ed.), Counselling psychology: Integrating theory, research and supervised practice (pp. 1-18). New York, NY: Routledge.

Coyle, A. (1998). Qualitative research in counseling psychology: Using the counseling interview as a research instrument. In P. Clarkson (Ed.), Counselling Psychology: Integrating theory, research and supervised practice (pp. 56-73). New York, NY: Routledge.

Davy, J. (2010). A narrative approach to counseling psychology. In R. Woolfe, S. Strawbridge, B. Douglas, \&W. Dryden. (Eds.), Handbook of counselling psychology (3rd ed., pp. 151-172). London: Sage.

Gergen, K. J. (2009). Relational being: beyond self and community. Oxford: Oxford University Press.

Gergen, K. J., \& Warhuus, L. (2001). Terapia como construção social: Características, reflexões, evoluções. In M. M. Gonçalves, \& O. F. Gonçalves (Orgs.), Psicoterapia, discurso e narrativa: A construção conversacional da mudança (pp. 27-64). Coimbra: Quarteto.

Goldstein, R. (2010). A narrative approach to counseling psychology. In R. Woolfe, S. Strawbridge, B. Douglas, \&W. Dryden. (Eds.), Handbook of counselling psychology (3rd ed., pp. 151-172). London: Sage.

Guanaes-Lorenzi, M. S. Moscheta, C. M. Corradi-Webster, \& L. V. Souza (Orgs.). (2014). Construcionismo social: Discurso, prática e produção do conhecimento. Rio de Janeiro, RJ: NOOS.

Hansen, J. I. C. (2012). Contemporary counseling psychology. In E. Altmaier \& J. Hansen (Eds.), The Oxford handbook of counseling psychology (pp. 917-922). New York, NY: Oxford University Press.

Haverkamp, B. E. (2012). The counseling relationship. In E. Altmaier \& J. Hansen (Eds.), The Oxford handbook of counseling psychology (pp. 32-70). New York, NY: Oxford University Press.

Ibañez, T. (2001). Psicologia social construccionista. México, DF: Universidad de Guadalajara.

Lyddon, WJ. (1998). Social construction in counselling psychology: A commentary and critique. Counselling Psychology Quarterly, 11(2), 215.

Martins, P. P. S., Santos, C. P., \& Rasera, E. F. (2013). A terapia focada na solução e suas aproximações ao discurso construcionista social. Estudos de Psicologia, 30(1), 111-120. https://dx.doi.org/10.1590/S0103166X2013000100012

McNamee, S. (2005). Modelos de terapia familiar como recursos conversacionais. Família e Comunidade, 2(1), 9-36.

McNamee, S. (2015). Radical presence: Alternatives to the therapeutic state, European Journal of Psychotherapy \& Counselling, 17(4), 373-383. https://doi.org/ 10.1080/13642537.2015.1094504

McNamee, S., \& Gergen, K. J. (1999). Relational responsibility: Resources for sustainable dialogue. Thousand Oaks: Sage.

Morato, H. T. P., Barreto, C. L. B.T, \& Nunes, A. P. (2009). (Orgs.), Aconselhamento psicológico numa perspectiva fenomenológica existencial: Uma introdução. Rio de Janeiro, RJ: Guanabara Koogan.

Neimeyer, R. (1998). Social constructionism in the counselling context. Counselling Psychology Quarterly, 11(2), 135.

Rasera, E. F., \& Japur, M. (2004). Desafios da aproximação do construcionismo social ao campo da psicoterapia. Estudos de Psicologia (Natal), 9(3), 431 439. https://doi.org/10.1590/S1413-294X2004000300005 
Rudes, J., \& Guterman, J. T. (2007), The value of social constructionism for the counseling profession: A reply to Hansen. Journal of Counseling \& Development, 85, 387-392. https://doi.org/10.1002/j.1556-6678.2007. tb00606.x

Sáez, M. T. (2006). Las terapias posmodernas: Una breve introducción a la terapia colaborativa, la terapia narrativa y la terapia centrada en soluciones. Psicología Conductual, 14(3), 511-532.

Shazer, S. (1985). Keys to solution in brief therapy. New York, NY: WW Norton.

Scheeffer, R. (1976). Estudos sobre aconselhamento psicológico. Rio de Janeiro, RJ: Editora Getúlio Vargas.

Schmidt, M. L. S. (2009). O nome, a taxonomia e o campo do aconselhamento psicológico. In H. T. P. Morato, C. L. B. T., \& A. P. Nunes (Orgs.), Aconselhamento Psicológico numa perspectiva fenomenológica existencial: Uma introdução (pp. 1-20). Rio de Janeiro, RJ: Guanabara Koogan.

Schmidt, M. L. S. (2015). Aconselhamento psicológico como área de fronteira. Psicologia USP, 26(3), 407413. https://doi.org/10.1590/0103-656420140033

Scorsolini-Comin, F., \& Santos, M. A. (2013). Counseling Psychology: A view of the scientific production in the Brazilian postgraduation. Revista Brasileira de Crescimento e Desenvolvimento Humano, 23(3), 338- 345.

Souza, L. V. (2014). Discurso construcionista social: Uma apresentação possível. In C. Guanaes-Lorenzi, M. S. Moscheta, C. M. Corradi-Webster, \& L. V. Souza (Orgs.), Construcionismo social: Discurso, prática e produção do conhecimento (pp. 49-72). Rio de Janeiro, RJ: NOOS.

Strawbridge, S., \& Woolfe, R. (2010). Counselling psychology: Origins, developments and challenges. In R. Woolfe, S. Strawbridge, B. Douglas, \& W. Dryden. (Eds.), Handbook of counselling psychology (3rd ed., pp. 3-22). London: Sage.

Strong, T. (2007). Accomplishments in social constructionist counseling: Micro-analytic and retrospective analyses. Qualitative Research in Psychology, 4(1-2), 85-105. https://doi.org/10.1080/14780880701473466

Strong, T. (2000). Six orienting ideas for collaborative counsellors. European Journal of Psychotherapy, Counselling and Health, 3(1), 25-42.

Strong, T. (2005). Understanding in counselling: A preliminary social constructionist and conversation analytic examination. British Journal of Guidance \& Counselling, 33(4), 513-533. https://doi. org/10.1080/03069880500327538

Strong, T., \& Nielsen, K. (2008). Constructive conversations: Revisiting selected developments with clients and counsellors. Counselling and Psychotherapy Research, 8(4), 253-260.

White, M., \& Epston, D. (1990). Médios narrativos para fines terapéuticos. Buenos Aires: Paidós.

Winslade, J. M. (2005) Utilising discursive positioning in counselling. British Journal of Guidance \& Counselling, 33(3), 351-364. https://doi.org/10.1080/03069880500179541

\section{Laura Vilela e Souza}

Docente do Departamento de Psicologia da Faculdade de Filosofia, Ciências e Letras da Universidade de São Paulo, Ribeirão Preto - SP. Brasil.

E-mail: laura@ffclrp.usp.br

Apoio financeiro FAPESP mediante auxílio regular de pesquisa Processo: 2015/08224-0.

Endereço para envio de correspondência:

Av. Bandeirantes, 3900. Bairro Monte Alegre. CEP: 14040-901.

Ribeirão Preto - SP. Brasil.

Recebido 05/09/2017

Reformulado 24/03/2018

Aprovado 11/04/2018 
Psicologia: Ciência e Profissão Abr/Jun. 2018 v. 38 n², 262-274.

Received 09/05/2017

Reformulated $03 / 24 / 2018$

Approved 04/11/2018

Recibido 05/09/2017

Reformulado 24/03/2018

Aceptado 11/04/2018

Como citar: Souza, L. V. (2018). Aconselhamento psicológico como construção social.

Psicologia: Ciência e Profissão, 38(2), 262-274. https://doi.org/10.1590/1982-3703003762017

How to cite: Souza, L. V. (2018). Counselling psychology as social construction.

Psicologia: Ciência e Profissão, 38(2), 262-274. https:// doi.org/10.1590/1982-3703003762017

Cómo citar: Souza, L. V. (2018). Asesoramiento psicológico como construcción social.

Psicologia: Ciência e Profissão, 38(2), 262-274. https://doi.org/10.1590/1982-3703003762017 